\title{
Разделение водно-солевых растворов фенилаланина электродиализом при использовании мембран с разной массовой долей сульфокатионообменной смолы
}

\author{
® 2021 Васильева В.И., Сауд А.М., Акберова Э.М. \\ Воронежский государственньий университет, Воронеж
}

Поступила в редакцию 15.06.2021 г.

DOI: $10.17308 /$ sorpchrom.2021.21/3634

\begin{abstract}
Установлены закономерности разделения водно-солевых растворов фенилаланина методом электродиализа, выбраны условия эффективного и селективного выделения целевого компонента подбором мембраны с заданными свойствами. В состав модельного раствора, имитирующего производственные воды в технологии микробиологического синтеза, входила ароматическая аминокислота фенилаланин $(0.05 \mathrm{M})$ и хлорид натрия $(0.01 \mathrm{M})$. Использованы экспериментальные мембраны с различной массовой долей сульфокатионообменной смолы. Гетерогенные ионообменные мембраны получены горячим вальцеванием гомогенизированной смеси измельченного ионообменника с полиэтиленом. Транспортные характеристики и особенности переноса компонентов разной природы через экспериментальные мембраны исследовали в гальваностатическом режиме с использованием семисекционного электродиализатора при его горизонтальной ориентации. Установлено влияние содержания ионообменника в мембране на особенности транспорта ионов минеральной соли и аминокислоты, величины фактора разделения и степени деминерализации растворов. Показано, что изменение содержания сульфокатионообменника в мембранах от 45 до 70 масс.\% при электродиализе смешанного раствора аминокислоты и минеральной соли позволяет в 1.5 раза увеличить скорость массопереноса минерального иона. Для всех экспериментальных мембран зависимости фактора разделения характеризуются экстремумами, приходящимися на интервал превышения величины предельного диффузионного тока $i_{\lim }$ в 2-3 раза. Максимальная эффективность разделения установлена для катионообменной мембраны с содержанием смолы 70\%. При превышении величины предельного диффузионного тока в 2 раза с ростом содержания смолы в мембране установлено увеличение фактора разделения в 1.5 раза. При этом степень деминерализации раствора для мембраны с максимальным содержанием ионообменника составляет 40-60\%. Возможность практически полной деминерализации раствора для мембраны с содержанием смолы 70 масс. \% установлена при превышении предельного тока в 6 раз.

Выявлена роль электроконвекции в увеличении потерь целевого продукта аминокислоты при сверхпредельных токовых режимах электродиализа. Показано, что основной причиной роста переноса аминокислоты через сульфокатионообменную мембрану в интенсивных токовых режимах является электроконвективное перемешивание раствора на межфазной границе, негативно влияющее на процесс диссоциации воды и разрушающее барьерное действие примембранных слоев раствора с высоким значением показателя рН. Установлена возможность глубокой деминерализации водно-солевого раствора фенилаланина с потерями целевого продукта не более $0.2 \%$ при использовании мембраны с массовой долей сульфокатионообменной смолы 70 масс.\% в интенсивных токовых режимах.
\end{abstract}

Ключевые слова: разделение, деминерализация, электродиализ, фенилаланин, минеральная соль, ионообменные мембраны, доля сульфокатионообменной смолы.

\section{Введение}

Достижения в области биотехнологии усилили потребность в разработке эффективных процессов разделения и очистки биохимических веществ и натуральных продуктов. Аминокислоты, которые находят применение в химической, сель- 
скохозяйственной, пищевой, косметической и фармацевтической промышленности, обычно производятся в процессе микробиологического синтеза, гидролиза белка или химического синтеза. Наиболее перспективен и экономически выгоден микробиологический синтез [1]. В результате микробиологического синтеза ароматической аминокислоты фенилаланина целевой продукт и производственные промывные воды содержат такие вещества как минеральные соли и сахар. Для решения проблемы выделения аминокислоты из смеси с сильными электролитами используются ионообменные и мембранные технологии [2-4]. Одним из перспективных мембранных методов является электродиализ с ионообменными мембранами [5-10].

Известно, что функциональные и транспортные характеристики ионообменных мембран определяются различными параметрами, такими как свойства их поверхности, структура, состав и способ изготовления [11-13]. Селективные и транспортные характеристики мембран для электродиализа можно оптимизировать, варьируя их состав (ионообменная смола, инертное связующее и добавки) и физические параметры (толщина, дисперсность, пористость и т.д.) [14-16]. При электродиализе разбавленных растворов существенно влияют на эффективность процесса разделения поверхностные свойства ионообменных мембран. Параметры поверхности мембраны оказывают сильное влияние на развитие эффектов, связанных с концентрационной поляризацией: в первую очередь, на интенсивность электроконвекции и генерации $\mathrm{H}^{+}$и $\mathrm{OH}^{-}$ионов, возникающих на границе раздела мембрана / раствор [17-19].

Целью данной работы является изучение влияния массовой доли сульфокатионообменной смолы на транспортные характеристики экспериментальных гетерогенных мембран и эффективность процесса разделения водно-солевых растворов фенилаланина методом электродиализа.

\section{Экспериментальная часть}

Объекты исследования. В работе использовали экспериментальные образцы гетерогенных сильнокислотных катионообменных мембран Ralex CM («MEGA» a.s., Чехия) с массовой долей ионообменной смолы от 45 до 70\% и высокоосновную анионообменную мембрану Ralex AM («MEGA» a.s., Чехия) с массовой долей ионообменной смолы 65\%. Гетерогенные ионообменные мембраны получены горячим вальцеванием гомогенизированной смеси измельченного ионообменника с полиэтиленом. Фиксированными группами катионоонообменных мембран и анионообменной мембраны являются сульфогруппы $-\mathrm{SO}_{3}{ }^{-}$и четвертичные аминогруппы $-\mathrm{N}^{+}\left(\mathrm{CH}_{3}\right)_{3}$, соответственно. В качестве армирующей ткани использован полиэстер (PES). Физикохимические свойства экспериментальных ионообменных мембран представлены в табл. 1. Сравнительный анализ физикохимических характеристик мембран показал, что с увеличением содержания ионообменника от 45 до 70\% увеличиваются величины полной обменной емкости ПОЕ на 25\%, и влагосодержания в 1.5 раза.

Исследование транспортных характеристик сульфокатионообменных мембран с разной массовой долей ионообменника проведено при электродиализном разделении модельных смешанных растворов ароматической аминокислоты фенилаланина $(0.05 \mathrm{M})$ и хлорида натрия $(0.01 \mathrm{M})$. В исследуемых водных растворах аминокислота находилась преимущественно в биполярной форме, так как $\mathrm{pH}$ растворов имел величины 5.6-6.0, близкие к значению изоэлектрической точки фенилаланина $\mathrm{pI}=5.91$. При этом содержание фенилаланина в катионной форме составляло $0.09-0.04 \%$, в анионной форме находилось 0.03-0.06\%, а в виде биполярных ионов 99.88-99.90\%.

Методы исследования. Электродиализ растворов выполняли в гальваностатическом режиме с использованием семисек 
Таблица. 1. Физико-химические свойства мембран с различной массовой долей сульфокатионообменной смолы

Table. 1. Physical and chemical properties of experimental membranes with different mass fractions of sulfonated cation-exchange resin

\begin{tabular}{|c|c|c|c|c|c|c|}
\hline Мембрана & $\begin{array}{c}\text { Содержание } \\
\text { ионообмен- } \\
\text { ника, масс. } \\
\%\end{array}$ & $\begin{array}{c}\text { ПОЕ, } \\
\text { мМоль/Г } \\
\text { набух.мембр }\end{array}$ & $\begin{array}{c}\text { ПОЕ, } \\
\text { ммоль/Г } \\
\text { сух.мембр }\end{array}$ & $\begin{array}{c}W, \Gamma_{\mathrm{H} 2 \mathrm{O}} / \Gamma \\
\text { набух.мембр } \\
\% \\
\%\end{array}$ & $d$, мкм & $\begin{array}{c}\text { Ионоген- } \\
\text { ные } \\
\text { группы }\end{array}$ \\
\hline \multirow{6}{*}{ Ralex CM } & 45 & $1.88 \pm 0.07$ & $2.66 \pm 0.09$ & $29 \pm 2$ & $540 \pm 20$ & \multirow{6}{*}{$-\mathrm{SO}_{3} \mathrm{H}$} \\
\hline & 50 & $1.90 \pm 0.02$ & $2.83 \pm 0.02$ & $33 \pm 1$ & $550 \pm 10$ & \\
\hline & 55 & $1.93 \pm 0.05$ & $3.00 \pm 0.07$ & $36 \pm 2$ & $585 \pm 5$ & \\
\hline & 60 & $2.07 \pm 0.04$ & $3.38 \pm 0.07$ & $39 \pm 1$ & $610 \pm 5$ & \\
\hline & 65 & $2.16 \pm 0.06$ & $3.76 \pm 0.09$ & $42 \pm 1$ & $655 \pm 5$ & \\
\hline & 70 & $2.34 \pm 0.05$ & $4.23 \pm 0.09$ & $45 \pm 2$ & $715 \pm 15$ & \\
\hline Ralex AM & 65 & $0.97 \pm 0.04$ & $1.57 \pm 0.04$ & $38 \pm 1$ & $690 \pm 10$ & $\mathrm{~N}^{+}(\mathrm{Cl}$ \\
\hline
\end{tabular}

ПОЕ - полная обменная емкость; $W$ - влагосодержание, $d$ - толщина мембраны в набухшем состоянии. TEC - total exchange capacity; $W$ - water content, $d$ - the thickness of the membrane in the swollen state.

ционного электродиализатора при его горизонтальной ориентации. Схема электродиализной ячейки представлена на рис. 1. В центральной секции деминерализации (4) активная площадь мембран составляла $4.2 \times 1.8 \mathrm{~cm}^{2}$; межмембранное расстояние 0.2 см. Во всех других секциях межмембранное расстояние составляло $1.0 \mathrm{~cm}$.

В секцию деминерализации (4) подавался исследуемый индивидуальный раствор хлорида натрия с концентрацией 0.01 моль/дм ${ }^{3}$, приготовленный из фиксанала соответствующим разведением, или его смешанный раствор с фенилаланином
$\mathrm{C}(\mathrm{Phe})=0.05$ моль $/$ дм $^{3}$. В смежных с исследуемой секциях концентрирования (3 и 5) находилась дистиллированная вода. Для создания условий избирательной поляризации исследуемых мембран $[20,21]$ в буферные камеры (2 и 6) подавались растворы хлорида натрия с концентрацией 0.10 моль/дм ${ }^{3}$, приготовленные по навеске. Через электродные камеры (1 и 7) пропускали 0.50 моль/дм ${ }^{3}$ раствор сульфата натрия, приготовленный по навеске. Линейная скорость подачи растворов в секцию деминерализации составляла $3.5 \times 10^{-4} \mathrm{M} / \mathrm{c}$.

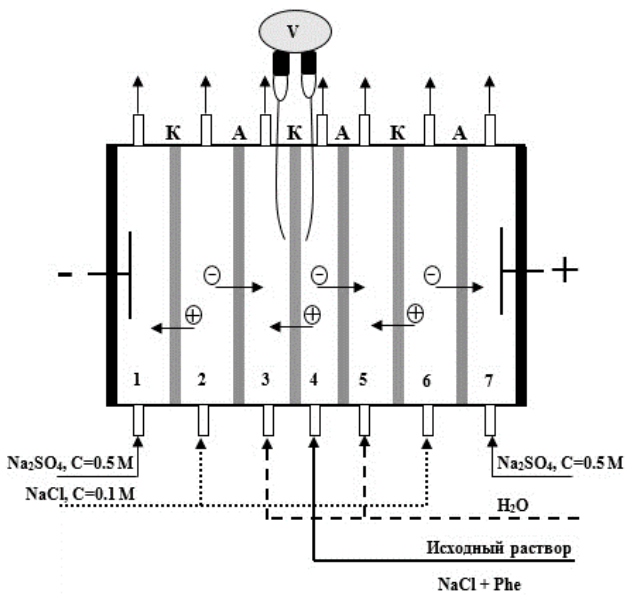

Рис. 1.Электродиализатор с чередующимися катионообменными (К) и анионообменными (А) мембранами. 1-7 - номера секций

Fig. 1. Electrodialyser with alternating cation-exchange $(\mathrm{K})$ and anion-exchange (A) membranes. (1-7) are numbers of sections 
Концентрацию фенилаланина определяли методом абсорбционной молекулярной спектроскопии на спектрофотометре СФ-2000 при $\lambda=259$ нм [22]. Концентрацию натрия измеряли методом эмиссионной пламенной фотометрии с помощью прибора ПАЖ-1 [23]. Для контроля величины $\mathrm{pH}$ растворов использовали лабораторной иономер И-160МИ (Россия) со стеклянным электродом.

Потоки компонентов через исследуемые катионообменные мембраны определяли по изменению их концентраций в растворе секции концентрирования (3):

$$
J=\frac{C V_{\text {oб }}}{S},
$$

где $\mathrm{J}$ - плотность потока компонента, моль/( $\left.\mathrm{cm}^{2} \cdot \mathrm{c}\right)$; С - концентрация компонента, моль/дм ${ }^{3} ; \mathrm{V}_{\text {об }}$ - объемная скорость раствора в секции концентрирования, дм $^{3} / \mathrm{c} ; \mathrm{S}$ - активная площадь мембраны, см² $^{2}$.

Для количественной оценки эффективности процесса разделения компонентов смешанного раствора аминокислоты и минеральной соли использовали фактор разделения $\mathrm{S}_{\mathrm{F}}$ [24], который определяли как отношение концентраций компонентов в секции концентрирования (3) к отношению концентраций компонентов в исходном растворе, поступающем в секцию деминерализации (4):

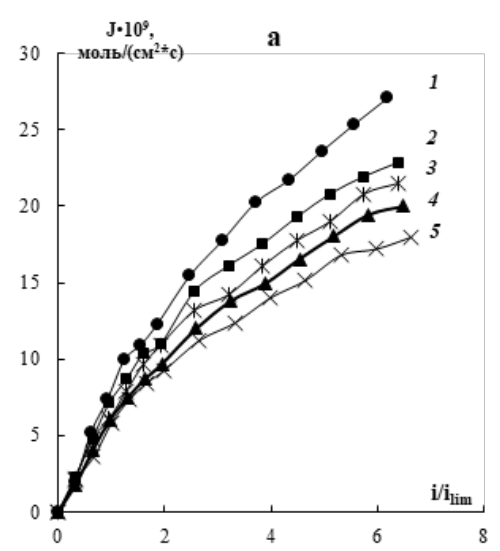

$$
S_{F}=\frac{\mathrm{C}_{3}(\mathrm{Na})}{\mathrm{C}_{3}(\mathrm{Phe})} \div \frac{\mathrm{C}_{0}(\mathrm{Na})}{\mathrm{C}_{0}(\mathrm{Phe})},
$$

где $\mathrm{C}_{3}$ - концентрации компонентов в секции концентрирования (3), моль/дм ${ }^{3} ; \mathrm{C}_{0}-$ концентрации компонентов в исходном растворе, моль/дм³; Phe - фенилаланин, $\mathrm{Na}$ - ионы натрия.

Расчет степени обессоливания а и потерь аминокислоты L проводился согласно [24]:

$$
\alpha=\frac{C_{0}-C_{i}}{C_{0}} \cdot 100 \%,
$$

где $\mathrm{C}_{0}$ - концентрация соли в исходном растворе, моль/дм ${ }^{3} ; \mathrm{C}_{\mathrm{i}}$ - концентрация соли на выходе из секции деминерализации при соответствующей величине плотности тока і, моль/дм

$$
L=\frac{C(\text { Phe })}{C_{0}(\text { Phe })} \cdot 100 \%,
$$

где $\mathrm{C}(\mathrm{Phe})$ - концентрация фенилаланина в секции концентрирования (3), моль/дм³ $\mathrm{C}_{0}(\mathrm{Phe})$ - концентрация фенилаланина в исходном растворе, моль/дм ${ }^{3}$.

\section{Обсуждение результатов}

Транспортные характеристики и механизм переноса компонентов разной природы через экспериментальные мембраны в широком диапазоне токов. На рис. 2 показано влияние плотности тока на транспортные характеристики экспериментальных сульфокатионообменных

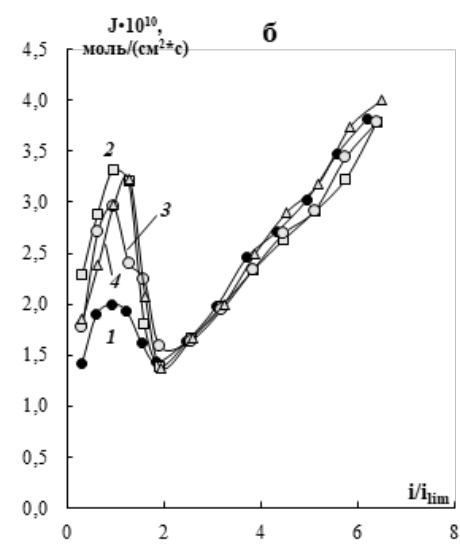

Рис. 2. Зависимости потоков ионов натрия (а) и фенилаланина (б) от безразмерной плотности тока через экспериментальные мембраны с массовой долей сульфокатионообменной смолы 70 (1), 65 (2), 60 (3), 55 (4) и 45 (5) \%. Плотность тока нормирована на величину предельного диффузионного тока $i_{l i m}$.

Fig. 2. Dependences of (a) sodium ions and (b) phenylalanine flows on the dimensionless current density through the experimental membranes with the mass fraction of sulfonated cationexchange resin of 70 (1), 65 (2), 60 (3), 55 (4), and $45(5) \%$. The current density is normalized to the value of the limiting diffusion current $i_{\text {lim }}$. 
мембран при электродиализе смешанного раствора аминокислоты и минеральной соли. Во всем исследуемом диапазоне токов массоперенос ионов натрия растет с увеличением плотности тока и на два порядка больше по сравнению с аминокислотой. Особенностью переноса фенилаланина через мембрану при электродиализе является наличие максимума на зависимости потока аминокислоты от плотности тока (рис. 2б). К ограничению потока аминокислоты через мембрану приводит перезарядка ионов амфолита, вызванная локальным изменением $\mathrm{pH}$ на межфазной границе при превышении предельной диффузионной плотности тока (барьерный эффект) $[25,26]$.

До достижения величины предельного диффузионного тока $i_{\text {lim }}$ по ионам натрия на катионообменной мембране незначительный перенос аминокислоты происходит вследствие электромиграции катионов аминокислоты, диффузионного переноса и электроосмотического механизма за счет сопряженного переноса аминокислоты в гидратной оболочке ионов натрия. При токах $i>i$ lim происходит процесс диссоциации воды на границе мембрана - раствор и транспорт аминокислоты через катионообменную мембрану снижается из-за барьерного действия при мембранных слоёв раствора с высоким значением $\mathrm{pH}$ на межфазной границе. Дальнейший рост массопереноса аминокислоты в работах $[25,27,28]$ объясняется эффектом облегченной электромиграции, обусловленным сопряженным транспортом аминокислоты с ионамипродуктами диссоциации воды.

На рис. 3 приведены результаты изменения показателя кислотности среды на выходе секции деминерализации и секции концентрирования со стороны катионообменной мембраны (65 масс. \%) с ростом плотности тока при электродиализе смеси хлорида натрия с фенилаланином. Полученные зависимости $\Delta \mathrm{pH}-i$ отражают изменения средних величин показателя кислотности среды во всем объеме секций деминерализации и концентрирования со стороны катионообменной мембраны. Кривая зависимости $\Delta \mathrm{pH}$ от плотности тока в секции деминерализации имеет максимум. Первоначальное повышение $\mathrm{pH}$ раствора связано с тем, что при относительно низких значениях тока скорость диссоциации воды для катионообменной мембраны выше, чем для анионообменной мембраны. Предельная плотность тока $i_{\text {lim }}=0.40 \mathrm{MA} / \mathrm{cm}^{2}$ сначала достигается на катионообменной мембране и возникает процесс диссоциации воды. Этому соответствует закисление раствора в смежной секции концентрирования вследствие переноса генерированных на межфазной границе $\mathrm{H}^{+}$ионов (рис. 3, кривая 1). При этом диссоциация воды на высокоосновной анионообменной мембране отсутствует. Однако при достижении на анионообменной мембране (65 масс.\%) величины тока $i_{\text {lim }}=0.65 \mathrm{MA} / \mathrm{cm}^{2}$ также начинается процесс диссоциации воды. Исследуемые экспериментальные катионообменные мембраны содержат функциональные сульфогруппы, каталитическая активность которых по отношению к диссоциации воды считается очень слабой (константа скорости реакции диссоциации воды $k_{l i m}=10^{-3} \mathrm{c}^{-1}$ ). Эта величина больше каталитической активности четвертичных аминогрупп $\left(k_{\text {lim }} \sim 0 \mathrm{c}^{-1}\right)$, которые входят в состав используемой высокоосновной анионообменной мембраны [29]. Однако, при интенсивных токовых режимах в поверхностном слое анионообменных мембран может происходить частичный гидролиз сильноосновных ионогенных групп четвертичных аммониевых оснований с образованием каталитически активных в реакции диссоциации воды фиксированных третичных и вторичных аминогрупп $[15,30]$. Поэтому количество $\mathrm{H}^{+}$ионов, поступающих в деминерализуемый раствор от поверхности анионообменной мембраны, больше, чем количество $\mathrm{OH}^{-}$ионов, доставляемых от 


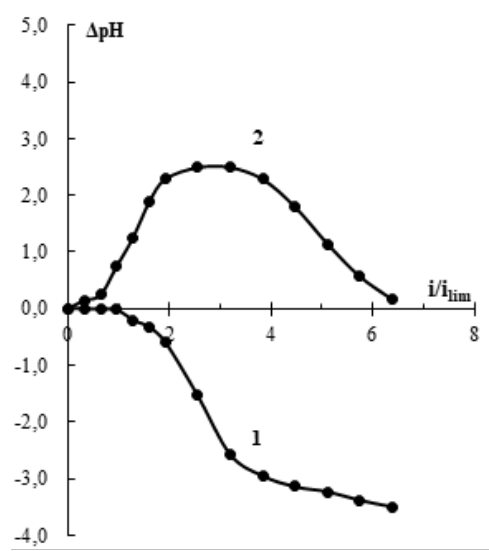

Рис. 3. Зависимость разности $\mathrm{pH}$ на выходе и входе для секции концентрирования (1)

и для секции деминерализации (2), образованных катионообменной мембраной

(65 масс. \%) и анионообменной мембраной (65 масс. \%), от плотности тока при электродиализе смешанного раствора хлорида натрия и фенилаланина. Плотность тока нормирована на величину предельного диффузионного тока $i_{\text {lim }}$.

Fig. 3. Dependence of the $\mathrm{pH}$ difference at the outlet and inlet for the concentration section (1) and for the demineralization section (2), formed by a cation-exchange membrane (65 wt.\%) and an anion-exchange membrane ( $65 \mathrm{wt} . \%)$ on the current density during the electrodialysis of a mixed solution of sodium chloride and phenylalanine. The current density is normalized to the value of the limiting diffusion current $i_{\text {lim }}$.

катионообменной мембраны. В результате этого наблюдается замедление скорости изменения кислотности среды и последующее падение величины $\mathrm{pH}$ раствора в секции деминерализации (рис. 3, кривая 2) до значений, соответствующих исходному раствору.

При превышении величины предельного диффузионного тока в 2 раза на катионообменной мембране установлен рост массопереноса фенилаланина (рис. 2б). В электромембранных системах с сульфокатионообменными мембранами диапазону токов $1.3 \leq i / i_{\text {lim }} \leq 2.0$ соответствует установление нестабильного режима электроконвекции, сопровождаемого появлением нестационарных электроконвективных вихрей [31]. Электроконвекция является эффектом, который не только вызывает значительное увеличение массопереноса, но также приводит к снижению скорости диссоциации воды $[32,33]$. Это воздействие объясняется тем, что увеличение электроконвективного перемешивания примыкающего к мембране слоя раствора приводит к увеличению концентрации ионов минеральной соли выше критического значения, при котором начинается генерация ионов $\mathrm{H}^{+}$и $\mathrm{OH}^{-}$на межфазной границе.

Уменьшение вследствие развития электроконвекции количества ионов гидроксила, образующихся при диссоциации воды на межфазной границе с катионообменной мембраной и участвующих в перезарядке аминокислоты с образованием анионов, способствует снижению и разрушению барьерного действия примембранных слоев раствора. Этот факт подтверждают замедление скорости изменения $\mathrm{pH}$ в растворе секции концентрирования (рис. 3 , кривая 1) и значительный перенос фенилаланина через мембрану (рис. 2б) с ростом плотности тока. Электроконвективная доставка дополнительного количества минеральной соли и аминокислоты из глубины раствора к поверхности мембраны является причиной того, что при токах $i>5 i_{\text {lim }}$ потоки аминокислоты через сульфокатионообменную мембрану (65 масс.\%) превышают максимальную величину в допредельном состоянии.

Влияние массовой доли ионообменника в мембране на количественные характеристики процесса разделения. В работах $[25,27]$ показана принципиальная 


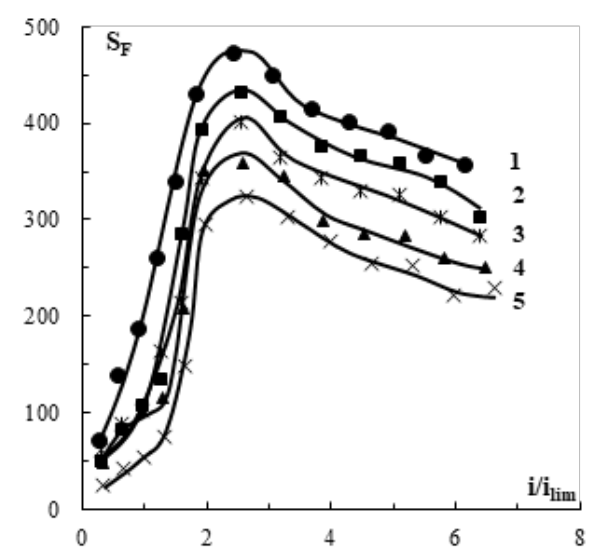

Рис. 4. Зависимость фактора разделения натрия и фенилаланина от безразмерной плотности тока для экспериментальных мембран с массовой долей сульфокатионообменника 70 (1), 65 (2), 60 (3), 55 (4) и 45 (5) \% при электродиализе смешанного раствора $\mathrm{NaCl}$ $(0.01 \mathrm{M})+$ Phe $(0.05 \mathrm{M})$. Плотность тока нормирована на величину предельного диффузионного тока $i_{\text {lim. }}$.

Fig. 4. Dependence of the separation factor of sodium and phenylalanine on the dimensionless current density for experimental membranes with a mass fraction of sulfonated cation-exchanger of 70 (1), 65 (2), 60 (3), 55 (4), and 45 (5)\% during the electrodialysis of a mixed $\mathrm{NaCl}$ $(0.01 \mathrm{M})+$ Phe $(0.05 \mathrm{M})$ solution. The current density is normalised to the value of the limiting diffusion current $i_{\text {lim }}$

возможность электромембранного разделения смеси аминокислоты и сильного электролита вследствие их различной природы. В водном растворе минеральная соль полностью диссоциирована, а аминокислота находится преимущественно в биполярной форме, не способной мигрировать под действием электрического тока. При включении постоянного электрического тока катионы натрия из секции деминерализации (4) мигрировали в секцию концентрирования (3), откуда их дальнейшая миграция ограничивалась анионообменной мембраной (рис. 1). Хлорид-ионы мигрировали из секции (4) в секцию концентрирования (5), откуда их дальнейшая электромиграция была ограничена катионообменной мембраной. Результатом является деминерализация исходного смешанного раствора.

Применение мембран с разным содержанием ионообменной смолы при электродиализе смешанного раствора аминокислоты и минерального электролита приводит к изменению параметров, характеризующих эффективность процесса. Известно, что различия в поверхностных и физико-химических свойствах отражаются на вольтамперных и транспортных характеристиках мембран [34]. Сравнительный анализ потоков ионов натрия при электродиализе смешанного раствора выявил увеличение массопереноса с ростом содержания сульфокатионообменной смолы в мембранах (рис. 2a). До достижения величин предельного диффузионного тока потоки ионов натрия различаются незначительно. В предельном состоянии для мембран с максимальным и минимальным содержанием ионообменника разница составила $28 \%$. Максимальное отличие величин потоков наблюдается в области сверхпредельных токовых режимов, где доминирующим механизмом транспорта компонентов является электроконвекция. С повышением в мембране содержания ионообменника от 45 до 70 масс.\% поток ионов натрия увеличивается в 1.5 раза при превышении величины предельного диффузионного тока в 6 раз.

При электродиализе потоки минерального электролита через мембраны превышали потоки аминокислоты на два порядка, что делает возможным их эффективное разделение. Зависимости фактора разделения натрия и фенилаланина $\mathrm{S}_{\mathrm{F}}$, 
Таблица 2. Степень обессоливания $\boldsymbol{a}$ и потери фенилаланина $\boldsymbol{L}$ при электродиализе раствора $\mathrm{NaCl}(0.01 \mathrm{M})+\mathrm{Phe}(0.05 \mathrm{M})$.

Table 2 . The degree of desalination $\boldsymbol{a}$ and phenylalanine loss $\boldsymbol{L}$ during the electrodialysis of a $\mathrm{NaCl}$ $(0.01 \mathrm{M})+$ Phe $(0.05 \mathrm{M})$ solution.

\begin{tabular}{|c|c|c|c|c|c|c|c|c|c|c|}
\hline \multirow{2}{*}{$\begin{array}{c}\text { Плот- } \\
\text { ность }\end{array}$} & \multicolumn{8}{|c|}{ Содержание ионообменника, масс. \% } \\
\cline { 2 - 12 } $\begin{array}{c}\text { тока } \\
i / i_{\text {lim }}\end{array}$ & $a, \%$ & $L, \%$ & $a, \%$ & $L, \%$ & $a, \%$ & $L, \%$ & $a, \%$ & $L, \%$ & $a, \%$ & $L, \%$ \\
\hline 0.6 & 18.3 & 0.145 & 22.0 & 0.081 & 22.0 & 0.083 & 22.1 & 0.094 & 24.6 & 0.063 \\
\hline 1.0 & 21.1 & 0.174 & 25.6 & 0.100 & 25.6 & 0.105 & 25.7 & 0.108 & 29.3 & 0.067 \\
\hline 1.6 & 27.6 & 0.095 & 33.0 & 0.065 & 33.0 & 0.074 & 34.4 & 0.061 & 34.9 & 0.053 \\
\hline 3.1 & 43.1 & 0.068 & 50.4 & 0.068 & 51.4 & 0.064 & 52.8 & 0.070 & 55.9 & 0.070 \\
\hline 6.2 & 85.2 & 0.131 & 94.5 & 0.131 & 96.3 & 0.128 & 97.7 & 0.128 & 98.6 & 0.129 \\
\hline
\end{tabular}

рассчитанного по выражению (2), от безразмерной плотности тока представлены на рис. 4. Для всех экспериментальных мембран зависимости фактора разделения характеризуются экстремумами, приходящимися на интервал превышения величины предельного диффузионного тока $i_{\lim }$ в 2-3 раза. Различия вследствие влияния массовой доли ионообменной смолы на коэффициент разделения проявляется только в его величине, а положение максимума не изменяется. Максимальная эффективность разделения наблюдается для мембраны с содержанием катионообменной смолы 70 масс.\%. При степени поляризации $i / i_{\text {lim }}=2.5$ с ростом содержания катионообменной смолы в мембране от 45 до 70 масс.\% установлено увеличение фактора разделения в 1.5 раза.

В интервале токов $2 \leq i / i_{\lim } \leq 3$, соответствующему наибольшему фактору разделения компонентов, степень обессоливания раствора для мембраны с максимальным содержанием ионообменника составляет 40-60\%, а для мембраны с минимальным содержанием 30-40\% (табл. 2). Деминерализация исследуемого раствора для мембраны с максимальным содержанием смолы становится практически полной при превышении величины предельного диффузионного тока в 6 раз. Потери аминокислоты во всем диапазоне токов для всех экспериментальных мембран составляют не более $0.2 \%$ (табл. 2 ).

\section{Заключение}

При анализе потоков катионов минеральной соли и аминокислоты через экспериментальные сульфокатионообменные мембраны в зависимости от плотности тока выявлено влияние содержания ионообменника в мембране на особенности переноса компонентов в процессе электродиализа модельных растворов, имитирующих промышленные воды технологии деминерализации аминокислот.

Установлено, что в интенсивных токовых режимах потери целевого продукта аминокислоты при использовании мембран с разным содержанием сульфокатионообменной смолы сопоставимы по величине и растут с увеличением плотности тока. Показано, что электроконвекция приводит к принципиальной интенсификации транспорта фенилаланина через сульфокатионообменные мембраны вследствие появления нового электроконвективного механизма транспорта аминокислоты и снижения барьерного действия примембранных слоев раствора с высоким значением показателя $\mathrm{pH}$.

Показаны преимущества мембраны с максимальным содержанием сульфокатионообменника, выражающиеся в достижении больших величин фактора разделения и степени деминерализации растворов при потерях целевого продукта не более $0.2 \%$. Использование мембраны с высоким содержанием ионообменника, 
характеризующейся более высокими значениями степени деминерализации и фактора разделения, позволяет сократить энергозатраты при очистке раствора аминокислоты от минеральной соли.

Исследование выполнено за счет гранта Российского научного фонда № 21-19-00397, https://rscf.ru/project/21-19-00397/

\section{Список литературы}

1. Быков В. А., Крылов И. А., Манаков М. Н. и др. Микробиологическое производство биологически активных веществ и препаратов. М. Высшая школа. 1987. 143 с.

2. Vasil'eva V., Goleva E., Pismenskaya N., Kozmai A. et al. // Sep. Purif. Technol. 2019. Vol. 210. pp. 48-59. DOI: https://doi.org/10.1016/j.seppur.2018.07.065

3. Kozmai A., Goleva E., Vasil'eva V., Nikonenko V. et al. // Membranes. 2019. Vol. 9. pp. 171-186. DOI: https://doi.org/10.3390/membranes9120171

4. Васильева В.И., Сауд А.М., Акберова Э.М. // Мембраны и мембранные технологии. 2021. T. 11. № 2. C. 110-118.

5. Grib H, Belhocine D, Lounici H, Pauss A, Mameri N. // J. Appl. Electrochem. 2000. Vol. 30/ pp. 259-262. DOI: https://doi.org/10.1023/ A: 1003990031853

6. Choi J, Oh S, Moon S. // J. Chem. Technol. Biotechnol. 2002. Vol. 77, pp. 785-792. DOI: https://doi.org/10.1002/jctb.638

7. Aghajanyan A.E., Hambardzumyan A.A., Vardanyan A.A., Saghiyan A.S. // Desalination. 2008. Vol. 228, pp. 237-244. DOI: https://doi.org/10.1016/j.desal.2007.10.012

8. Елисеева Т.В., Харина А.Ю., Воронюк И.В. и др. // Сорбиионные и хроматографические прочессы. 2013. Т. 13. № 5. С. 647-654.

9. Sun Z, Gao X, Zhang Y, Gao C. // Desalin. Water Treat. 2016. Vol. 57. pp. 2230422310. DOI: https://doi.org/10.1080/19443 994.2015.1137082

10. Харина А.Ю., Елисеев С.Я. // Конденсированные среды и межфазные гранииы. 2017. T. 19. № 1. C. 126-132.

11. Mondal S., Griffiths I.M., Ramon G.Z. // J. Membr. Sci. 2019. Vol. 588. Art. No. 117166. DOI: $\quad$ https://doi.org/10.1016/j.memsci. 2019.06.006

12. Stenina I., Golubenko D., Nikonenko V., Yaroslavtsev A. // Int. J. Mol. Sci. 2020. Vol. 21. Art. No. 5517. DOI: https://doi.org/10.3390/ijms21155517

13. Ковалев Н.В., Карпенко Т.В., Шельдешов Н.В., Заболоцкий В.И. // Мембраны и мембранные технологии. 2020. Т. 10. № 6. C. 418-427.

14. Ahmad M., Qaiser A.A., Huda N.U., Saeed A. // $R S C A d v$. 2020. Vol. 56010, pp. 3029. DOI: https://doi.org/10.1039/C9RA 06178A

15. Zabolotskiy V.I., But A.Yu., Vasil'eva V.I., Akberova E.M. et al. // J. Membr. Sci. 2017. Vol. 526. pp. 60-72. DOI: https://doi.org/10.1016/j.memsci.2016.12.028

16. Васильева В.И., Жильцова А.В., Акберова Э.М., Фатаева А.И. // Конденсированные среды и межфазные границы. 2014. Т. 16. № 3. C. $257-261$.

17. Porozhnyy M.V., Shkirskaya S.A., Butylskii D.Y., Dotsenko V.V. et al. // Electrochim. Acta. 2021. Vol. 370. Art. No. 137689. DOI: https://doi.org/10.1016/j.electacta.2020.137689

18. Васильева В.И., Акберова Э.М., Заболоцкий В.И. // Электрохимия. 2017. Т. 53. № 4. C. 452-465.

19. Akberova E.M., Vasil'eva V.I., Zabolotsky V.I., Novak L. // J. Membr. Sci. 2018. Vol. 566. pp. 317-328. DOI: https://doi.org/10.1016/ j.memsci.2018.08.042

20. Rosenberg N.W., Tirrell C.E. // Ind. Eng. Chem. 1957. Vol. 49. pp. 780-784. DOI: https://doi.org/10.1021/ie50568a047

21. Исаев Н.И., Шапошник В.А. Синтез и свойства ионообменных материалов. М. Наука. 1968. С. 256-261.

22. Котова Д.Л., Крысанова Т.А., Елисеева Т.В. Спектрофотометрическое определение аминокислот в водных растворах. Воронеж. ВГУ. 2004. $55 \mathrm{c}$.

23. Saud A.M., Smagin M.A., Vasil'eva V.I. // Заводская лаборатория. Диагностика материалов. 2020. Т. 86. №. 1. С. 13-18.

24. Хванг С.-Т., Каммермейер К. Мембранные процессы разделения. М. Химия. $1981.464 \mathrm{c}$.

25. Шапошник В.А., Елисеева Т.В., Селеменов В.Ф. // Электрохимия. 1993. Т. 29. № 6. C. 794-795.

26. Васильева В.И., Елисеева Т.В. // Электрохимия. 2000. Т. 36. № 11. С. 35-40. 
27. Elisseeva T.V., Shaposhnik V.A., Luschik I.G. // Desalination. 2002. Vol. 149. pp. 405409. DOI: https://doi.org/10.1016/S00119164(02)00763-4

28. Eliseeva T.V., Shaposhnik V.A. // Russ J Electrochem. 2000. Vol. 36, pp. 64-67. DOI: https://doi.org/10.1007/BF02757798

29. Заболоцкий В.И., Шельдешов Н.В., Гнусин Н.П. // Успехи химии. 1988. Т. 57. № 8. С. 1403-1414.

30. Заболоцкий В.И., Бугаков В.В., Шарафан М.В., Чермит Р.X. // Электрохимия. 2012. T. 48. № 6. C. 721-731.
31. Vasil'eva V., Zabolotsky V., Shaposhnik V., Zhiltsova A. et al. // Desalin. Water Treat. 2010. Vol. 14. pp. 214-219. DOI: https://doi.org/10.5004/dwt.2010.1030

32. Belova E., Lopatkova G., Pismenskaya N., Nikonenko V et al. // Desalination. 2006. Vol. 199. pp. 59-61. DOI: https://doi.org/10.1016/j.desal.2006.03.142

33. Zyryanova S., Mareev S., Gil V. et al. // Int. J. Mol. Sci. 2020. Vol. 21. Art. No. 973. DOI: https://doi.org/10.3390/ijms21030973

34. Akberova E.M., Vasil'eva V.I. // Electrochem. Commun. 2020. Vol. 111. Art. No. 106659. DOI: https://doi.org/10.1016/j.elecom.2020.106659

\title{
Separation of phenylalanine aqueous salt solutions by electrodialysis using membranes with different mass fractions of sulfonated cation-exchange resin
}

\author{
(R 2021 Vasil’eva V.I., Saud A.M., Akberova E.M. \\ Voronezh State University, Voronezh
}

The research established the regularities for the separation of phenylalanine aqueous salt solutions by electrodialysis. It also determined the conditions for the effective and selective isolation of the target component by selecting a membrane with the desired properties. The composition of the model solution simulating industrial water in the technology of microbiological synthesis included an aromatic amino acid, phenylalanine $(0.05 \mathrm{M})$, and sodium chloride $(0.01 \mathrm{M})$. Experimental membranes with different mass fractions of sulfonated cation-exchange resin were used. Heterogeneous ion-exchange membranes were obtained by hot rolling of a homogenised mixture of a crushed ion-exchanger and polyethylene. The transport characteristics and features of the transfer of components of different nature through the experimental membranes were studied in a galvanostatic mode using a seven-section electrodialyser which was horizontally oriented. It was established that the content of the ion exchanger in the membrane influences the features of the transport of mineral salt and amino acid ions, the value of the separation factor, and the degree of solutions demineralization.

It was shown that the change in the content of the sulfonated cation-exchanger in the membranes from 45 to $70 \mathrm{wt} \% \%$ during the electrodialysis of a mixed solution of an amino acid and a mineral salt makes it possible to increase the rate of mass transfer of a mineral ion by 1.5 times. For all experimental membranes, the separation factor dependences are characterised by extrema corresponding to the interval exceeding the limiting diffusion current $i_{\text {lim }}$ by 2-3 times. The maximum separation efficiency was set for a cation exchange membrane with a $70 \%$ content of resin. It was found that when the limiting diffusion current was exceeded by a factor of 2 while the content of resin in the membrane increased, the separation factor increased by 1.5 times. Additionally, the degree of demineralization of the solution for the membrane with the maximum content of the ion exchanger was $40-60 \%$. The possibility of almost complete demineralization of the solution for the membrane with a content of resin of $70 \mathrm{wt} . \%$ was established when the maximum current was exceeded by 6 times.

The study revealed the role of electroconvection in the increase in the loss of the target product of the amino acid with overlimiting current modes of electrodialysis. It was shown that the main reason for the increase in the transfer of amino acids through the sulphonated cation-exchange membrane in intense current modes is the electroconvective mixing of the solution at the interface, which negatively affects the process of water dissociation and destroys the barrier effect of the near-membrane layers of the solution with a high $\mathrm{pH}$ value.

The research established the possibility of deep demineralization of phenylalanine aqueous salt solution with a loss of the target product of no more than $0.2 \%$ using a membrane with a mass fraction of a sulfonated cation-exchange resin of $70 \mathrm{wt} . \%$ in intense current modes.

Keywords: separation, demineralization, electrodialysis, phenylalanine, mineral salt, ion exchange membranes, fraction of sulfonated cation-exchange resin. 


\section{References}

1. Bykov V.A., Krylov I.A., Manakov M.N. et al. Mikrobiologicheskoe proizvodstvo biologicheski aktivnyh veshhestv i preparatov. Moscow, Vysshaja shkola, 1987, 143 p.

2. Vasil'eva V., Goleva E., Pismenskaya N., Kozmai A. et al., Sep. Purif. Technol., 2019, Vol. 210, pp. 48-59. DOI: https://doi.org/10.1016/j.seppur.2018.07.065

3. Kozmai A., Goleva E., Vasil'eva V., Nikonenko V. et al., Membranes, 2019, Vol. 9, pp. 171-186. DOI: https://doi.org/10.3390/membranes9120171

4. Vasil'eva V.I., Saud A.M., Akberova E.M., Membr. Membr. Technol., 2021, Vol. 3, No 2, pp. 98-106. https://doi.org/10.1134/ S2517751621020074

5. Grib H., Belhocine D., Lounici H., Pauss A. et al., J. Appl. Electrochem., 2000, Vol. 30, pp. 259-262. DOI: https://doi.org/10.1023/ A: 1003990031853

6. Choi J., Oh S., Moon S., J. Chem. Technol. Biotechnol., 2002, Vol. 77, pp. 785-792. DOI: https://doi.org/10.1002/jctb.638

7. Aghajanyan A.E., Hambardzumyan A.A., Vardanyan A.A., Saghiyan A.S., Desalination, 2008, Vol. 228, pp. 237-244. DOI: https://doi.org/10.1016/j.desal.2007.10.012

8. Eliseeva T.V., Kharina A.Y., Voronyuk I.V. et al., Sorbtsionnye I Khromatograficheskiye Protsessy, 2013, Vol. 13, No 5, pp. 647654.

9. Sun Z., Gao X., Zhang Y., Gao C., Desalin. Water Treat., 2016, Vol. 57, pp. 2230422310. DOI: https://doi.org/10.1080/19443994. 2015.1137082

10. Kharina A.Y., Eliseeva T.V., Kondens. Sredy Mezhfaznye Granitsy, 2017, Vol. 19, No 1, pp. 126-132.

11. Mondal S., Griffiths I.M., Ramon G.Z., J. Membr. Sci., 2019, Vol. 588, Art. No. 117166. DOI: https://doi.org/10.1016/j.memsci.2019.06.006

12. Stenina I., Golubenko D., Nikonenko V., Yaroslavtsev A., Int. J. Mol. Sci., 2020, Vol. 21, Art. No. 5517. DOI: https://doi.org/10.3390 /ijms21155517

13. Kovalev N.V., Karpenko T.V., Shel'deshov N.V., Zabolotskiy V.I., Membr. Membr. Technol., 2020, Vol. 2, No 6, pp. 391398. https://doi.org/10.1134/S2517751620 060050
14. Ahmad M., Qaiser A.A., Huda N.U., Saeed A., RSC Adv., 2020, Vol. 56010, pp. 3029. DOI: https://doi.org/10.1039/ C9RA06178A

15. Zabolotskiy V.I., But A.Yu., Vasil'eva V.I., Akberova E.M., et al., J. Membr. Sci., 2017, Vol. 526, pp. 60-72. DOI: https://doi.org/10.1016/j.memsci.2016.12.028

16. Vasil'eva V.I., Zhiltsova A.V., Akberova E.M., Fataeva A.I., Kondens. Sredy Mezhfaznye Granitsy, 2014, Vol. 16, No 3, pp. 257-261.

17. Porozhnyy M.V., Shkirskaya S.A., Butylskii D.Y., Dotsenko V.V. et al., Electrochim. Acta, 2021, Vol.370, Art. No. 137689. DOI: https://doi.org/10.1016/j.electacta.2020.137689

18. Vasil'eva V.I., Akberova E.M., Zabolotskii V.I., Russ. J. Electrochem., 2017, Vol. 53, No 4, pp. 398-410. DOI: https://doi.org/10.1134/S1023193517040127

19. Akberova E.M., Vasil'eva V.I., Zabolotsky V.I., Novak L., J. Membr. Sci., 2018, Vol. 566, pp. 317-328. DOI: https://doi.org/10.1016/j.memsci.2018.08.042

20. Rosenberg N.W., Tirrell C.E., Ind. Eng. Chem. 1957, Vol. 49, pp. 780-784. DOI: https://doi.org/10.1021/ie50568a047

21. Isaev N.I., Shaposhnik V.A. Sintez i svoistva ionoobmennykh materialov. Moscow, Nauka, 1968, pp. 256-261.

22. Kotova D.L., Krysanova T.A., Eliseeva T.V. Spektrofotometricheskoe opredelenie aminokislot v vodnyh rastvorah. Voronezh, Voronezh State University, 2004, 55 p.

23. Saud A.M., Smagin M.A., Vasil'eva V.I., Industrial laboratory. Diagnostics of materials, 2020, Vol. 86, pp. 13-8.

24. Hwang S. T., Kammermeyer K. Membranes in separations. New York, John Wiley $\&$ Sons, 1975, $526 \mathrm{p}$.

25. Shaposhnik V.A., Eliseeva T.V., Selemenov V.F., Russ. J. Electrochem., 1993, Vol. 29, № 6, pp. 794-795.

26. Vasil'eva V. I., Eliseeva T. V., Russ. J. Electrochem., 2000, Vol. 36, No 11, pp. 30-35. DOI: https://doi.org/10.1007/BF02757792

27. Elisseeva T.V., Shaposhnik V.A., Luschik I.G., Desalination, 2002, Vol. 149, pp. 405409. DOI: https://doi.org/10.1016/S00119164(02)00763-4

28. Eliseeva T.V., Shaposhnik V.A., Russ J Electrochem., 2000, Vol. 36, pp. 64-67. DOI: https://doi.org/10.1007/BF02757798 
29.Zabolotskii V.I., Shel'deshov N.V., Gnusin N.P., Uspekhi khimii, 1988, Vol. 57, No. 8, pp. 1403-1414.

30.Zabolotskii V.I., Bugakov V.V., Sharafan M.V., Chermit R.K., Russ. J. Electrochem., 2012, Vol. 48, No 6, pp. 650-659. DOI: https://doi.org/10.1134/S1023193512060158

31. Vasil'eva V., Zabolotsky V., Shaposhnik V., Zhiltsova A. et al., Desalin. Water Treat., 2010, Vol. 14, pp. 214-219. DOI: https://doi.org/10.5004/dwt.2010.1030

Васильева Вера Ивановна - профессор кафедры аналитической химии, д.х.н., Воронежский государственный университет, Воронеж

Сауд Али Мунир - аспирант кафедры аналитической химии, Воронежский государственный университет, Воронеж

Акберова Эльмара Маликовна - ведущий инженер кафедры аналитической химии, к.х.н., Воронежский государственный университет, Воронеж
32. Belova E., Lopatkova G., Pismenskaya N., Nikonenko V. et al., Desalination, 2006,Vol. 199, pp. 59-61. DOI: https://doi.org/10.1016/j.desal.2006.03.142

33. Zyryanova S., Mareev S., Gil V. et al., Int. J. Mol. Sci., 2020, Vol. 21, Art. No. 973. DOI: https://doi.org/10.3390/ijms21030973

34. Akberova E. M., Vasil'eva V. I., Electrochem. Commun., 2020, Vol. 111, Art. No. 106659.

DOI: https://doi.org/10.1016/j.elecom.2020.106659

Vasil'eva Vera I. - prof., grand Ph.D (chemistry), department of analytical chemistry, Voronezh State University, Voronezh, e-mail: viv155@mail.ru

Saud Ali M. - the postgraduate student, department of analytical chemistry, Voronezh State University, $\quad$ Voronezh, e-mail: ali_saud1900@live.com

Akberova EImara M. - Ph.D. (chemistry), leading engineer, department of analytical chemistry, Voronezh State University, Voronezh, email: elmara_09@inbox.ru 